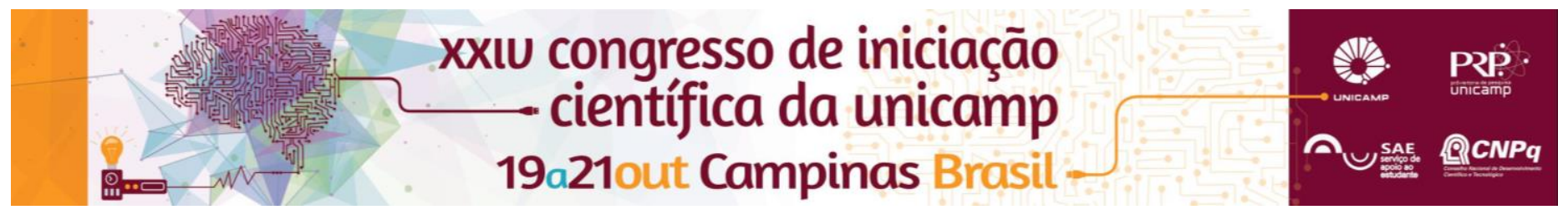

\title{
MULTIMODALIDADE NO ENSINO DE PORTUGUÊS PARA SURDOS: O USO DE GLOSSÁRIOS DIGITAIS
}

Isabella de A. Martins*, Isadora de S.Meletti*, João Pedro A. da S. Francol ${ }^{\star}$, Jéssica Vasconcelos Dorta, Profa. Dra. Ivani Rodrigues Silva (FCM/UNICAMP)

\begin{abstract}
Resumo
Uma das principais dificuldades da comunidade surda em relação à aprendizagem da língua portuguesa está na aquisição de vocabulário. Os dicionários tradicionais não costumam ser eficientes para que os alunos entendam o significado das palavras, uma vez que apresentam verbetes com explicações em língua portuguesa, a partir de outras palavras desconhecidas por eles. Não se trata apenas de desconhecer o sinal da palavra em Libras, mas de compreender o significado dela. Dessa forma, a internet, por apresentar recursos multimodais como imagens estáticas, imagens em movimento, vídeos, etc., é uma grande aliada dos surdos na busca por esses significados. Pensando nisso, o presente projeto de pesquisa buscou investigar como as tecnologias digitais podem auxiliar o processo de aprendizagem do português como segunda língua por essa comunidade, principalmente, no que se refere à aquisição de vocabulários através de glossários construídos a partir de atividades contextualizadas, como é o caso dos Memes.
\end{abstract}

\section{Palavras-chave}

Aprendizagem de Português, Glossários Digitais, Novas tecnologias.

\section{Introdução}

É inegável que o uso das tecnologias digitais, em especial, as móveis tem crescido exponencialmente. Essas tecnologias já não estão mais confinadas em um espaço específico. Na realidade, elas têm acompanhado a mobilidade dos usuários. A conexão sem fio e as redes $3 \mathrm{~g}$ e $4 \mathrm{~g}$ têm permitido que grande parte dos usuários esteja sempre conectada. Se essa dinamicidade mudou o jeito de viver dos ouvintes, para os surdos as mudanças e possibilidades são ainda mais perceptivas. Por isso, o objetivo deste trabalho foi investigar como as tecnologias digitais podem auxiliar 0 processo de aprendizagem do português como segunda língua por essa comunidade, no que diz respeito à aquisição de vocabulário. Dessa forma, trabalhamos com a produção de memes, explorando recursos tecnológicos oferecidos pelo computador conectado à internet.

\section{Resultados e Discussão}

Percebemos ao longo dos primeiros meses de pesquisa que os surdos estão muito pouco acostumados a lidar educacionalmente com essas tecnologias. O uso de computadores, notebooks e smartphones, por exemplo, é em grande parte limitado ao uso de redes sociais e aplicativos de mensagens. No entanto, uma vez que os surdos começam a se apropriar dessas tecnologias e dos recursos que elas oferecem, muda também a forma como eles se relacionam com elas.

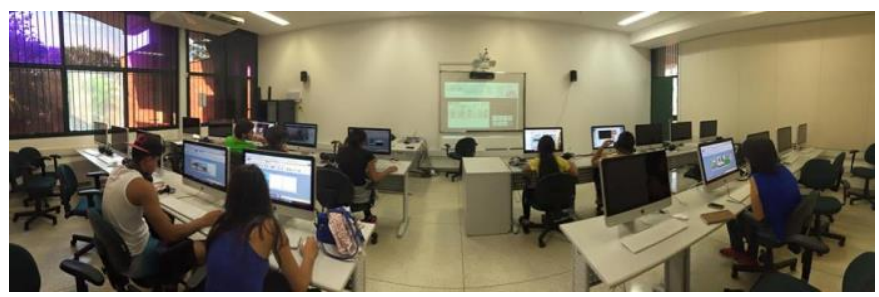

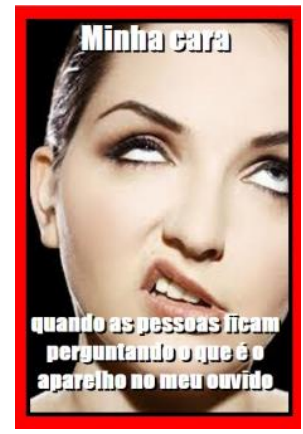

Figura 1. Meme L.

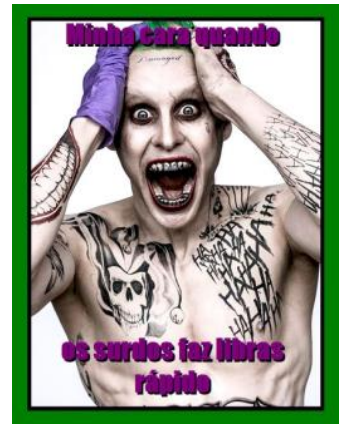

Figura 2. Meme JP

\section{Conclusões}

Os computadores e outras tecnologias digitais conectadas à internet possibilitam reunir em um mesmo espaço uma infinidade de linguagens e ferramentas que, quando usados de maneira crítica, impactam positivamente o modo como os alunos surdos adquirem vocabulário e aprendem o português escrito.

\section{Agradecimentos}

Agradecemos à Pró-Reitoria de Pesquisa (PRP) Unicamp pelas bolsas concedidas aos alunos surdos do Ensino Médio, autores e participantes da pesquisa.

ROJO, R. H. R.; ALMEIDA, E. de M. (Orgs.). Multiletramentos na escola. São Paulo: Parábola Editorial, 2012.
Figura 1. Laboratório de informática no IEL - UNICAMP. DOI: 10.19146/pibic-2016-52027 